\title{
$\angle$ Out-of-court system: a fair fast track to savings of time and money
}

\author{
Sandeep Kandregula, MBBS, and Bharat Guthikonda, MD, MBA \\ Department of Neurosurgery, LSU Health Shreveport, Louisiana
}

$\mathrm{L}$ ITIGATION and lawsuits are very common events in the career of a neurosurgeon. Nearly every neurosurgeon will be involved in at least one malpractice claim in their career; sometimes these claims will be frivolous. ${ }^{1}$ More often than not, the litigation in neurosurgery will be in cases of spinal surgery, where the patient's expectations and the actual outcomes are often disparate. There is often a disconnect between how the patient expects to be after surgery and the common surgical outcomes. ${ }^{1-3}$ Although sometimes inadequate care or fault in the treatment does occur, the majority of the claims seen in spine surgery cases are due to a heightened functional outcome expectation and the impact of the known or unexpected complications on the patient's personal or professional life. ${ }^{4}$ Neurosurgeons and all physicians experience significant emotional, physical, and mental sequelae from malpractice claims. As a result, malpractice litigation is one of the most frequent causes of physician burnout and the practice of defensive medicine. Compared with other medical specialties, neurosurgery often has among the highest malpractice insurance premiums and indemnities paid per claim. ${ }^{5}$ The amount of time and expense for resolution of malpractice claims is quite significant for both parties. A variety of malpractice reforms have been enacted to avoid frivolous litigation. These include tort reform, medical review panels, and filing fees. These reforms are intended to provide a fair and efficient solution that protects patients who have fallen victim to malpractice while at the same time protecting physicians against the consequences of unwarranted litigation.

Debono et al. studied the implications of an alternate judicial system in France called the "out-of-court" system. ${ }^{6}$ This quick and efficient mechanism involves a twostage decision process. After a patient files a lawsuit, the Commission for Conciliation and Compensation (CCI) appoints a medical expert team that performs an indepen- dent review of the case. The CCI team formulates a preliminary opinion regarding the claim. They then finalize the decision based upon their review of the case details and the medical expert team's opinion. The CCI is chaired by a magistrate and includes patient welfare association representatives, insurers, and physician experts. The CCI is expected to arrive at a resolution decision within 6 months of the claim initiation, a timespan that is significantly shorter than the length of a standard court proceeding. If unsatisfied with the CCI's recommendation, the plaintiff has the option of proceeding to a traditional court hearing.?

In the study reported by Debono et al., the authors analyzed 193 closed malpractice claims against private neurosurgeons practicing spine surgery in France. The average age of the patient was 51.1 years. Interestingly, one-third of the patients had a prior history of spine surgery $(n=54$, $27.9 \%$ ), and thus were known to be in a higher risk patient population than patients who had not undergone previous spine surgery. The lumbar spine was the most common (74.6\%) location of surgery in litigation-involved cases and, surprisingly to us, lumbar discectomy (32.2\%) was the most common procedure performed in these patients who initiated litigation.

Following the conclusion of the first stage, when a decision was reached by the medical expert team, $34.2 \%$ of cases were found to involve negligence, $32.1 \%$ were found the be no fault, and the remainder were felt to entail strict liability or be the result of severe nosocomial infection. There were significant discrepancies seen between the findings of the medical expert team and those of the CCI. The CCI concluded proven negligence in only $13.5 \%$ of cases, compared with $34.2 \%$ according to the medical expert team. These discrepancies were likely due to the multidisciplinary input of the $\mathrm{CCI}$ and the delicate balance between scientific reasoning and other stakeholders' pri- 
orities on the CCI. Following the final verdict of the CCI, $11.5 \%$ of plaintiffs were unsatisfied and elected (within their rights) to proceed with a traditional court trial.

The findings of this article were consistent with those reported for other studies evaluating the litigation of neurosurgeons and specifically involving spine surgery. ${ }^{1,2,8}$ The main advantage of the alternate system in France described by Debono et al. is the drastically shorter time frame to achieve resolution. Daniels et al. reported an average time of 5 years for a verdict in favor of a defendant, 5.1 years for a plaintiff verdict, and 3.4 years for settlement, compared with 6 months for the out-of-court system detailed in the current article. ${ }^{2}$ That shorter time span entails a massive advantage for those involved in these cases, as the tangible effects (such as time and money) and intangible effects (such as defensive medicine practice and stress-induced health-related problems for the physician, possibly leading to burnout and early retirement) of an extra 3-5 years awaiting resolution can likely not be accurately measured. ${ }^{2}$

Severe complications, delay in diagnosis, and delay in treatment were the main factors contributing to a favorable plaintiff verdict. A mean of $\$ 4,045,205 \pm \$ 6,804,647$ was paid toward plaintiff verdicts and a mean of $\$ 1,930,278 \pm$ $\$ 2,113,593$ toward settlements. ${ }^{2}$ Rovit et al. reported that an average of $\$ 28,440$ in legal fees was charged if the case did not proceed to trial. This amount rose dramatically to $\$ 73,000$ per case if a trial was needed. ${ }^{8}$ In this light, the out-of-court system proposed in the article by Debono et al. provides a free-of-charge service leading to at least a preliminary decision, where both parties could settle without a trial. In a 5-year study conducted in the early 2000 s, a total of $\$ 60$ million was paid on behalf of only the study population of neurosurgeons for malpractice claims. ${ }^{8}$ The potential cost savings from the out-of-court system could be astronomical.

A similar system exists in the United States and is called the medical review panel (MRP) process. ${ }^{9}$ Both systems are intended to expedite the legal process and decrease the cost of litigation for both parties. The French out-of-court system has the jurisdiction for finalizing a decision for the claim, whereas the US MRP cannot render a binding decision. However, the MRP's influence has been shown to be significant in terms of the low frequency with which cases proceed to trial with an unfavorable MRP decision. States in which there are caps on economic/noneconomic damages, tort reform, and pretrial screening panels (like the MRP) are considered favorable for the practice of neurosurgery. ${ }^{10}$

We commend the authors for introducing the concept of the out-of-court medical legal system and reviewing its implication for spinal neurosurgery. The authors extolled the merits of the system while also transparently noting the weaknesses. Like many excellent papers, this study also did have some limitations. It would have been even more informative if the authors had provided the average amounts of claims/indemnities paid for economic and noneconomic damages. This information would have been particularly interesting to correlate with severity of complications and proof of negligence. As the authors mention, the data reported are from a single insurer. As such, the information reported may not provide the best representation of the total population. Inclusion of multiple insurers, including those patients treated at public hospitals, would also have been of interest. In spite of this minor study design issue, we truly congratulate Debono et al. for a job well done!

https://thejns.org/doi/abs/10.3171/2020.8.FOCUS20764

\section{References}

1. Elsamadicy AA, Sergesketter AR, Frakes MD, Lad SP. Review of neurosurgery medical professional liability claims in the United States. Neurosurgery. 2018;83(5):997-1006.

2. Daniels AH, Ruttiman R, Eltorai AEM, et al. Malpractice litigation following spine surgery. J Neurosurg Spine. 2017;27(4):470-475.

3. Taylor CL. Neurosurgical practice liability: relative risk by procedure type. Neurosurgery. 2014;75(6):609-613.

4. Maroon JC. Catastrophic cardiovascular complications from medical malpractice stress syndrome. J Neurosurg. 2019;130(6):2081-2085.

5. Agarwal R, Gupta A, Gupta S. The impact of tort reform on defensive medicine, quality of care, and physician supply: a systematic review. Health Serv Res. 2019;54(4):851-859.

6. Debono B, Gerson C, Houselstein T, et al. Litigations following spinal neurosurgery in France: "out-of-court system," therapeutic hazard, and welfare state. Neurosurg Focus. 2020;49(5):E11.

7. Thouvenin D. French medical malpractice compensation since the act of March 4, 2002: liability rules combined with indemnification rules and correlated with several kinds of proceedings. Drexel L Rev. 2011;4:165.

8. Rovit RL, Simon AS, Drew J, et al. Neurosurgical experience with malpractice litigation: an analysis of closed claims against neurosurgeons in New York State, 1999 through 2003. J Neurosurg. 2007;106(6):1108-1114.

9. Kosty J, Jiang B, LeFever DC, et al. The medical review panel in Louisiana neurosurgery and beyond. Neurosurgery. 2019;85(6):E992-E1001.

10. LeFever D, Demand A, Kandregula S, et al. Status of current medicolegal reform in the United States: a neurosurgical perspective. Neurosurg Focus. 2020;49(5):E5.

\section{Disclosures}

The authors report no conflict of interest.

\section{Correspondence}

Bharat Guthikonda: bguthi@1suhsc.edu.

\section{INCLUDE WHEN CITING}

DOI: 10.3171/2020.8.FOCUS20764. 